NBER WORKING PAPER SERIES

\title{
INTERGENERATIONAL TRANSFER, HUMAN CAPITAL AND LONG-TERM GROWTH IN CHINA UNDER THE ONE CHILD POLICY
}

\author{
Xi Zhu \\ John Whalley \\ Xiliang Zhao \\ Working Paper 19160 \\ http://www.nber.org/papers/w19160 \\ NATIONAL BUREAU OF ECONOMIC RESEARCH \\ 1050 Massachusetts Avenue \\ Cambridge, MA 02138 \\ June 2013
}

We are grateful to the Ontario Research Fund (ORF), the National Natural Science Foundation of China (71073102, 71273171, 71273172), and Shanghai Pujiang Program (12PJC067) for financial support, and to a seminar group at Western University for comments. The views expressed herein are those of the authors and do not necessarily reflect the views of the National Bureau of Economic Research.

NBER working papers are circulated for discussion and comment purposes. They have not been peerreviewed or been subject to the review by the NBER Board of Directors that accompanies official NBER publications.

(C) 2013 by Xi Zhu, John Whalley, and Xiliang Zhao. All rights reserved. Short sections of text, not to exceed two paragraphs, may be quoted without explicit permission provided that full credit, including (C) notice, is given to the source. 
Intergenerational Transfer, Human Capital and Long-term Growth in China under the One Child Policy

Xi Zhu, John Whalley, and Xiliang Zhao

NBER Working Paper No. 19160

June 2013

JEL No. J13,O11,O53

\begin{abstract}
We argue that the demographic changes caused by the one child policy (OCP) may not harm China's long-term growth. This attributes to the higher human capital induced by the intergenerational transfer arrangement under China's poor-functioning formal social security system. Parents raise their children and depend on them for support when they reach an advanced age. The decrease in the number of children prompted by the OCP resulted in parents investing more in their children's educations to ensure retirement consumption. In addition, decreased childcare costs strengthen educational investment through an income effect. Using a calibrated model, a benchmark with the OCP is compared to three counterfactual experiments without the OCP. The output under the OCP is expected to be about 4 percent higher than it would be without the OCP in 2025 under moderate estimates. The output gain comes from a greatly increased educational investment driven by fewer children (11.4 years of schooling rather than 8.1). Our model sheds new light on the prospects of China's long-term growth by emphasizing the OCP's growth enhancing role through human capital formation under the intergenerational transfer arrangement.
\end{abstract}

$\mathrm{Xi}$ Zhu

Antai College of Economics \& Management

Shanghai Jiao Tong University

Antai Building

535 Fahuazhen Road, Shanghai, China

200052

zhuxi97@gmail.com

John Whalley

Department of Economics

Social Science Centre

University of Western Ontario

London, ON N6A 5C2

CANADA

and NBER

jwhalley@uwo.ca
Xiliang Zhao

Department of Economics

Xiamen University

zhaoxiliang@tsinghua.org.cn 


\title{
Intergenerational Transfer, Human Capital and Long-term Growth in China under the One Child Policy
}

\begin{abstract}
We argue that the demographic changes caused by the one child policy (OCP) may not harm China's long-term growth. This attributes to the higher human capital induced by the intergenerational transfer arrangement under China's poor-functioning formal social security system. Parents raise their children and depend on them for support when they reach an advanced age. The decrease in the number of children prompted by the OCP resulted in parents investing more in their children's educations to ensure retirement consumption. In addition, decreased childcare costs strengthen educational investment through an income effect. Using a calibrated model, a benchmark with the OCP is compared to three counterfactual experiments without the OCP. The output under the OCP is expected to be about 4 percent higher than it would be without the OCP in 2025 under moderate estimates. The output gain comes from a greatly increased educational investment driven by fewer children (11.4 years of schooling rather than 8.1 ). Our model sheds new light on the prospects of China's long-term growth by emphasizing the OCP's growth enhancing role through human capital formation under the intergenerational transfer arrangement.
\end{abstract}

Keywords: intergenerational transfer, human capital, growth, demographic transition JEL Classification: J13, O11, O53

\section{Introduction}

China's government introduced the one child policy (OCP) in 1979 with the aim of controlling rapid population growth. As a result, China experienced a great demographic transition from high to low rates of fertility and mortality in the twentieth century (McElroy and Yang, 2000). According to UN world population 
prospects, there will be an increase in the population of young adults (and its share of the total population) before the 2020s, a decrease in the childhood population after the 1990s and a continuous increase in the elderly population after 1979. In the demographic transition, the elderly population is expected to exceed the working-age population by 2025. ${ }^{1}$ (See figure 1 )

\section{Insert figure 1 here}

How the OCP would affect China's future growth has become one of most widely considered questions regarding China's future growth. We first analyze the relationship between population and economic growth. There have been debates on this topic for hundreds of years. In his most influential book, Malthus (1798) asserts that given limited resources, population growth hampers economic growth. Boserup (1981) is more optimistic. He argues that population may have a scale effect that is beneficial to economic growth. The Malthusian model treats technological progress as exogenous, which has also been challenged in more recent studies. Romer (1986, 1990) and Jones (1999) emphasize that the role of population in economic growth becomes neutral or even positive when allowing technological progress to be endogenous. Thus, these theories offer no consensus about the OCP's impact.

Other economists have tried to conduct empirical investigations on this topic. Li and Zhang (2007) show that the birth rate has had a negative influence on economic growth, also suggesting that the OCP is growth enhancing. Bloom and Williamson (1998) highlight the role of the working-age population. According to their studies on East Asia, the OCP would first enhance economic growth through a fast increase in

\footnotetext{
${ }^{1}$ In our calibrated model, we define the generational groups as childhood ( 0 -24 years), young adulthood (25-49 years) and elderly (50 or more years). Typical definitions place childhood from 0 to 14 years, youth at 15 to 64 years and old age at 65 or more years, but the trend of China's demographic transition is robust to different definitions.
} 
the working-age population, which is called a demographic gift. However, this demographic gift would dissipate with the rising volume of elderly individuals in the near future, as depicted in Figure 1. The idea of a disappearing demographic gift in China has become increasingly popular in the past several years, particularly in light of the labor shortages experienced in some coastal provinces. Cai (2010) and Zhang et al. (2011) view it as a sign that the Lewis Turning Point has been reached and express concern over the challenges to China’s future growth.

We argue that the demographic changes caused by the OCP may not harm China's long-term growth as conventionally believed, given parents’ behavior response as reflected in their children's educational investment in the OCP under China's intergenerational transfer arrangement. Within a poorly functioning formal social security system, Chinese parents raise their children and depend on them for support once they have reached an advanced age. Thus, the decrease in the number of children prompted by the OCP results in parents investing more in their children's education to ensure retirement consumption. In addition, the decreased childcare costs strengthen the educational investment through an income effect. Using a calibrated model, we compare a benchmark with the OCP to a counterfactual experiment without the OCP. The model sheds new light on the prospects for China's long-term growth.

The framework is a three-period overlapping generation economy under the OCP. In the model, only the parents work for wage income and they take care of the children and the elderly. The children depend on their parents for support. As a reward, the parents then depend on their children upon reaching an elderly state. We assume that the parents ask for a share of their children's future wage income in the internal agreement. The parents make decisions and supply labor to the production sector. Childcare costs are fixed, so they choose their own consumption and the level 
of the children's education. The parents have an incentive to invest in their children's education because it can increase their children's future wage income, which will be shared by parents who have retired in that period.

By plugging China's demographic structure as shaped by the OCP into the model, we calibrate the main parameters of the model using data from 1975 to $2000 .^{2}$ We then conduct three counterfactual experiments without the OCP. Under moderate estimates, we find that the output in 2025 would decrease by 4.1 percent without the OCP despite an increase in the working population of 28.2 percent without the policy. Our model contributes to the literature in several respects. First and most importantly, it shows that the OCP is growth enhancing in the long term under the intergenerational transfer arrangement. It is a well-known fact that Chinese parents depend on their children for retirement consumption under a poorly functioning social security system (Banejee et al., 2010). However, there has been little attention paid to the implication for China's human capital and growth. Unlike other studies, our model treats children's education as an investment rather than a consumption good. This implies that the intergenerational transfer arrangement would urge parents to invest more in their children's education with the OCP in effect, which could by and large offset the adverse effects of the disappearing demographic gift. Our results are consistent with those of Li and Zhang (2007), which support the neo-Malthusian school of thought.

Second, we provide an explanation of Chinese parents' stronger preference for more educated children compared to other countries. Li et al. (2008) and Rosenzweig and Zhang (2009) find that family size has a negative effect for average child quality(education). This is usually interpreted as a quantity-quality tradeoff originated

\footnotetext{
${ }^{2}$ The time period in the model is 25 years.
} 
by Becker and Lewis (1973), which assumes that both the number and education of children can increase parents' utility. Yet it does not explain why Chinese parents prefer education to a greater degree than parents from many other countries. We state that under the intergenerational transfer arrangement, parents share the return of education investment in children, thus they have a stronger investment incentive to ensure their retirement consumption when fertility is constrained by the OCP. It also partly explains the great increase in the education of the Chinese working-age population since the 1990s.

Three recent papers are most related to our study, and our study supplements the literature. Liao (2012) uses a calibrated general equilibrium model and finds that the OCP promotes human capital and increase per capita output. In her model, the incentives for investing in children's education come from the price effect (general equilibrium) and parents’ preference (quantity-quality tradeoff). Wei and Zhang (2011) study the competitive saving motive (for a son's relative attractiveness in the marriage market) created by the rising sex ratio caused by the OCP. They show that the competitive saving motive explains much of China's high savings rate. Neither of these studies takes the intergenerational transfer into account. Banejee et al. (2010) notes the popularity of parents' dependence on their children and introduces it into a life cycle model to explain Chinese households' savings behavior. Their focus is on the OCP's impact on savings, however, and they do not consider its influence on education or the long-term growth effects.

The remainder of this paper is organized as follows. In Section 2 we provide some background. We summarize the OCP and its impact on demographic structure and provide evidence of parents' dependence on their children. In Section 3 we describe the model. In Section 4 we discuss the calibration. The experiments and results are 
provided in Section 5 and Section 6 concludes the paper.

\section{Background}

\section{The One Child Policy and China's Demographic Structure}

China's OCP was formally introduced as a family planning policy that was introduced in 1978 and initially applied to first-born children beginning in 1979. It officially restricted married urban couples to having only one child, while allowing exemptions in several cases including twins, ethnic minorities, rural couples and parents without any siblings themselves. It was created by the government to alleviate economic, social and environmental problems in China.

The policy has been strongly enforced mainly through fines that are imposed based on family income and other factors ${ }^{3}$, but the implementation varies from location to location. As mentioned above, the majority of provinces now permit two parents who were only children themselves to have two children. All non-Han ethnic groups are usually allowed to have two or more children. Han Chinese living in rural areas are also permitted to have two children if their first child is female.

After the introduction of the OCP, the fertility rate in China fell from 2.63 births per woman in 1980 to 1.61 in 2009. According to authorities' claims, the policy has prevented about 400 million births in 30 years ${ }^{4}$, which proved the policy to be remarkably effective. There has been some debate regarding whether there had already been a sharp reduction in the fertility rate in the early 1970s (five births per woman) in China. Thus, the policy is probably only partially responsible for the

\footnotetext{
${ }^{3}$ There are also some benefits and financial rewards for single-child families including a small amount of child allowance that continues until the child reaches age 14 and priority access to schools and health care.

${ }^{4} 400$ million births prevented by one-child policy, October 28, 2011, People’s Daily.
} 
reduction. However, it has played an important role in shaping China’s demographic structure since the end of the 1970s.

Insert figure 2 here

As figure 2 shows, the proportion of the group aged 24 years and below in the total population has declined since 1975, from 58.42\% in 1975 to $40.53 \%$ in 2000 . According to the medium estimates of the world population prospects ${ }^{5}$, this trend will continue, declining to $26.80 \%$ in 2025 , and $21.42 \%$ in 2050 . Meanwhile, the proportion of the group aged 49 years and above has continued to increase since 1975, from $27.48 \%$ in 1975 to $38.02 \%$ in 2010 . It is expected to reach $52.01 \%$ in 2050 . This demographic structure has strong implications for China’s future growth.

\section{Intergenerational Transfer Arrangement}

There is a widely held belief that Chinese parents view their children as a form of pension for when they are elderly. Although China has made a great deal of effort in pension reform, Herd, Hu and Koen (2010) point out that under current rules, effective replacement rates are fairly low and projected to decline further, both for rural and urban residents, which may be difficult to sustain with the elderly living increasingly less frequently with their descendants. Furthermore, as the countryside ages, the problems can become even worse.

A recent survey in China confirms the inefficiency of the pension system. Until 2010, only $24.1 \%$ of the elderly relied mainly on a pension while $40.7 \%$ depended on

\footnotetext{
${ }^{5}$ The future population of each country is projected starting with an estimated population for July 1, 2010. To project future population, the UN Population Division uses assumptions regarding future trends in fertility, mortality and international migration. Because future trends cannot be known with certainty, a number of projection variants are produced. We use the medium fertility projection variant. For further details, refer to "Assumptions Underlying the 2010 Revision." (http://esa.un.org/wpp/Documentation/pdf/WPP2010_ASSUMPTIONS_AND_VARI ANTS.pdf)
} 
their family members for support. ${ }^{6}$ Using data from the China Household Retirement Longitudinal Survey (CHRLS), Benerjee et al. (2010) find that as expected, more than half of the surveyed elderly live with their children and parents are more likely to live with their children if one of the parents is in poor health, which is consistent with the belief that children take care of their parents when the latter are elderly. The advantage of having many children is consistent with the observation that the fraction of parents living with at least one adult child increases from $56 \%$ for parents with only one child to over $70 \%$ for those with seven or eight children. ${ }^{7}$

\section{Educational Transformation}

While the educational status of the working-age population has continued to rise in the past six decades, its structure has undergone major change since the 1990s. Figure 3 shows the average years of primary, secondary and tertiary schooling for the working-age population based on Barro and Lee (2010). It is clear that tertiary education gains much higher growth and contributes most to the rise in educational attainment in the past two decades. This is also documented in $\mathrm{Li}$ et al. (2011). Furthermore, China still exhibits great potential in increasing their human capital compared to the US, especially in tertiary education (see figure 4).

Insert figure 3 and 4 here

As the World Bank (2012) reports, hundreds of millions of unskilled Chinese workers joined the global labor force as part of China’s “opening up” strategy in the 1980s and 1990s. Now, tens of millions of tertiary-educated Chinese workers will join

\footnotetext{
${ }^{6}$ Over $20 \%$ of China's elderly rely on pension, CRI, Oct 23, 2012, http://www.china.org.cn/china/2012-10/23/content_26880415.htm

${ }^{7}$ The CHRLES is a survey at the household level that only samples the elderly. Benerjee et al. (2010) restrict the sample to those who had their first child during the 1970s and early 1980s.
} 
the global workforce to significantly expand the global supply of skill-intensive products. The number of college graduates could swell by 200 million over the next two decades - more than the entire labor force of the United States.

\section{The Model}

We imagine a simple life cycle divided into three periods: childhood, young adulthood (parents), and old adulthood (retired). It is assumed that children will not work, but rather that they will depend on their parents for support, including subsistence consumption (childcare costs) and educational investment. As a reward, they agree to provide part of their future wage income to their parents' retirement consumption when they enter the workforce in the next period.

The parents supply labor to gain wage income and make decisions. They are responsible for their children's subsistence consumption and for their parents' retirement consumption. They independently choose their own consumption and their children's educational investment. Educational investment costs money, but will increase children's wage in the next period. We assume that fertility is exogenously determined under the OCP. That is, parents take the number of children as given.

\section{The Basic Model}

Define $L_{t}^{z}, e_{t}^{z}$ as the population and educational attainment of generation $z$, when $z \in\{c, y, o\}$ represents children, young adults and old adults. The survival rate of children and the life expectancy of old adults might change over time, so we allow $L_{t}^{c} \neq L_{t+1}^{y} \neq L_{t+2}^{o}$. This is easy to check using Table $1 .^{8}$ We assume that the education

\footnotetext{
${ }^{8}$ Because our period is 25 years, the quantity of survival rate and life expectancy is a little different compared to the regular concept.
} 
level remains constant as children grow up into young adults, i.e. $e_{t}^{c}=e_{t+1}^{y}$.

The lifetime utility function of young adults at $t$ is $U\left(c_{t}^{y}, c_{t+1}^{o}\right)$, where $c_{t}^{z}$ is generation $z$ 's consumption in period $t$. We do not add childhood's subsistence consumption here, because it is assumed to be the same for everyone and provided by parents. We also assume that neither children's nor their own education level enters an agent's utility function. It is not uncommon for children's education to enter the parents’ preference, given Becker and Lewis (1973), but here we ignore it to focus on the effect of intergenerational transfers.

We assume a constant return to scale (CRS) Cobb-Douglas production function:

$$
\begin{aligned}
Y_{t} & =A_{t} K_{t}^{\alpha}\left(H_{t}^{y}\right)^{1-\alpha} \\
& =A_{t} K_{t}^{\alpha}\left[L_{t}^{y} \exp \left(\delta e_{t}^{y}\right)\right]^{1-\alpha} .
\end{aligned}
$$

where output is determined by technology $A_{t}$, capital stock $K_{t}$ and human capital $H_{t}^{y}$. For human capital, we follow the growth literature (e.g. Hall and Jones, 1999; Bils and Klenow, 2000) by setting $H_{t}^{y}=L_{t}^{y} \exp \left(\delta e_{t}^{y}\right)$. This specification is consistent with the common Mincer (1974) equation, which implies that the log of the individual's wage is linearly related to that individual's years of schooling. It could also be interpreted that an additional year of schooling raises a worker's efficiency proportionally by $\delta$. Choosing the exponential form could allow us to draw on the large volume of micro evidence on $\delta$ to quantify the impact of schooling on human capital and growth.

Assume that capital accumulation and technology progress are exogenous, and the only income that a young adult earns is his wage income $w_{t} L_{t}^{y} \equiv(1-\alpha) Y_{t}$. As discussed above, a young adult would support their retired parents and children. To simplify the model, we assume that they would share a fixed proportion of their wage 
income $(\lambda)$ with their parents and pay a constant childcare cost $\left(c^{\text {sub }}\right)$ for each of their children. The remaining part is allocated between their own consumption and the children's educational investment. We assume that the educational cost for each child's additional years of schooling is $p_{t}$, and parents make an equal investment for each child.

Thus, the young adults maximize utility subject to the budget constraint.

$$
\begin{gathered}
\max _{c_{t}^{y}, e_{t}^{c}} U\left(c_{t}^{y}, c_{t+1}^{o}\right) . \\
\text { st. } c_{t}^{y}+p_{t} \exp \left(\delta e_{t}^{c}\right) L_{t}^{c}=(1-\lambda)(1-\alpha) Y_{t}-L_{t}^{c} c^{s u b}, \\
c_{t+1}^{o}=\lambda(1-\alpha) A_{t+1} K_{t+1}^{\alpha}\left(\exp \left(\delta e_{t+1}^{y}\right) L_{t+1}^{y}\right)^{1-\alpha} .
\end{gathered}
$$

Here, educational cost is $p_{t} \exp \left(\delta e_{t}^{c}\right)$, which includes tuition and other costs (such as time and effort). As Bils and Klenow (2000) suggest, we assume that tuition costs increase with the opportunity cost (wage) of schooling because in reality, tuition rises with the level of education.

We assume that preferences are CRRA; that is,

$$
U\left(c_{t}^{y}, c_{t+1}^{o}\right)=\frac{1}{1-\gamma}\left(\left(c_{t}^{y}\right)^{1-\gamma}-1\right)+\beta \frac{1}{1-\gamma}\left(\left(c_{t+1}^{o}\right)^{1-\gamma}-1\right)
$$

where $\beta$ is the subjective discount factor with respect to the utility of consumption and $\frac{1}{\gamma}$ denotes the elasticity of inter-temporal substitution. The first order condition with respect to the young adults’ own consumption and their children's educational investment implies the following condition

$$
\begin{aligned}
& \beta\left(\frac{c_{t+1}^{o}}{c_{t}^{y}}\right)^{-\gamma} \cdot \lambda(1-\alpha) A_{t+1} K_{t+1}^{\alpha} \exp \left[(1-\alpha) \delta e_{t}^{c}\right]\left(L_{t+1}^{y}\right)^{-\alpha}(1-\alpha) \delta \cdot \pi_{t+1} \\
& =p_{t} \exp \left(\delta e_{t}^{c}\right) \delta
\end{aligned}
$$

where the left is the marginal benefit of increasing children's educational attainment 
and the right is its marginal cost. The marginal benefit consists of a discounted factor, marginal output of education and survival rate of children $\pi_{t+1}$ (which equals $\left.L_{t+1}^{y} / L_{t}^{c}\right)$. The parents sacrifice their current consumption and spend it on their children's education to enjoy more retirement consumption from the higher future wage income earned by more highly educated children. Expressing $c_{t+1}^{o}$ by $e_{t+1}^{y}$ (or $\left.e_{t}^{c}\right)$ in this equation results in

$$
\beta \frac{\left(c_{t}^{y}\right)^{\gamma}}{\left[\exp \left(\delta e_{t}^{c}\right) L_{t+1}^{y}\right]^{\alpha+\gamma-\alpha \gamma}}\left(\lambda(1-\alpha) A_{t+1} K_{t+1}^{\alpha}\right)^{1-\gamma}(1-\alpha) \cdot L_{t+1}^{y} / L_{t}^{c}=p_{t}
$$

Parents' dependence on children for retirement consumption does influence children's education. When $\lambda$ (proportion of shared wage income) increases, children’s educational level increases.

\section{The OCP's Impact on Education and Growth}

Now consider the impact of the OCP. From the budget constraint (1) and first-order condition (2), it is clear that under stationary population growth $\left(L_{t}^{c}=L_{t}^{y}=L_{t}^{o}\right)$, the educational investment would also be stationary. The enforcement of the OCP decreases the number of $L_{t}^{c}$, which have two channels through which to affect children's education: (1) income effect. That is, there would be fewer mouths to feed (the childcare cost, $L_{t}^{c} c^{\text {sub }}$, decreases) and the parents' real income increases; (2) substitution effect. That is, with fewer children, the parents would increase their children's educational investment to ensure shared wage income during retirement. This is a materialistic motive for the well-known quantity-quality tradeoff.

For simplicity, the changes of technology, capital, cost of education and childcare, 
survival rate are assumed to be constant. Then it is easy to show that ${ }^{9}$

Proposition 1. When $\lambda, A_{t}, K_{t}, p_{t}, c^{\text {sub }}, \pi_{t+1}$ remain constant, the enforcement of the OCP (1) increases each child's educational level, and (2) even increases output.

It is a little surprising that the output would increase under the OCP. Why the response in the human capital can over compensate? Intuitively, this is caused by the income effect (higher real income and less childcare cost) besides the substitution effect (quantity-quality trade-off). Thus, the dependence on children will make parents make strong response to the demographic change caused by the OCP, which will offset the negative effect on economic output caused by a decreasing labor force. The proposition has strong implications for China’s long-term growth. It predicts an relatively optimistic future.

Proposition 1 depends on the assumption that parameter in tuition cost, $p_{t}$, is constant. In reality, $p_{t}$ might increase very fast when the educational attainment reaches a certain level. In that case, OCP's impact on growth could turn to be moderate or even negative. However, since China's current educational attainment is relatively low compared to the developed countries, the positive impact could still dominate in the near future.

\section{Discussion of the Model}

\section{Sharing Rule}

We assume a linear sharing rule on wage income to describe the intergenerational transfer arrangement between young adults and their retired parents. Although we think it reasonable based on what happens in China, there could be alternative choices.

\footnotetext{
${ }^{9}$ Proof is provided in Appendix.
} 
One alternative is a linear sharing rule on wage. That is, young adults promise the elderly an average retirement consumption of $\lambda w_{t}$.(replacement ratio) The model becomes

$$
\begin{aligned}
& \max _{c_{t}^{y}, e_{t}^{c}} U\left(c_{t}^{y}, c_{t+1}^{o}\right) . \\
& \text { st. } c_{t}^{y}+p_{t} \exp \left(\delta e_{t}^{c}\right) L_{t}^{c}=(1-\alpha) Y_{t}-c_{t+1}^{o}-L_{t}^{c} c^{s u b}, \\
& c_{t+1}^{o}=\lambda(1-\alpha) A_{t+1} K_{t+1}^{\alpha} L_{t+1}^{y 1-\alpha} e_{t}^{c 1-\alpha}\left(L_{t+1}^{o} / L_{t+1}^{y}\right) .
\end{aligned}
$$

This model is similar to our basic model when population growth is stationary $\left(L_{t+1}^{y}=L_{t+1}^{o}\right)$. However, the enforcement of the OCP will make $L_{t}^{c}<L_{t}^{y}$. Thus, it has the advantage of underlining the burden of the increasing elderly population caused by the OCP. When the elderly population increases, education will increase reflecting its high return.

Another alternative is that young adults promise a fixed amount of retirement consumption ( $\left.c^{\text {old }}\right)$ for each parent. The model becomes

$$
\begin{aligned}
& \max _{c_{t}^{y}, e_{t}^{c}} U\left(c_{t}^{y}, c_{t+1}^{o}\right) . \\
& \text { st. } c_{t}^{y}+p_{t} e_{t}^{c} L_{t}^{c}=(1-\lambda)(1-\alpha) A_{t} K_{t}^{\alpha}\left(e_{t}^{y} L_{t}^{y}\right)^{1-\alpha}-L_{t}^{c} c^{\text {sub }}, \\
& c_{t+1}^{o}=c^{o l d} L_{t}^{o} .
\end{aligned}
$$

In this case, the young adults would have no incentive to invest in children's education because their retirement consumption is ensured. This model makes sense if we apply some revisions and let children make decisions on their consumption and education and pay back their education costs as a loan to parents. The elderly's retirement consumption seems like a lump sum tax to them, which would give them more incentive to gain a higher education. We assume that the parents determine children’s investment.

\section{Educational Credit Constraints}

We assume that households face a credit constraint on educational investment, such 
that parents must cover all of the costs in the current period. While credit for education in China has grown in recent years, it still amounts to a small fraction. Most children's tuitions and other educational costs are paid by their parents.

\section{Incentive for Educational Investment}

The standard model of human capital investments, such as that provided by Ben-Porath (1967), assumes that the individual chooses the investment (in terms of time) under perfect capital market conditions, and that the only margin of choice is between market work and schooling. Bils and Klenow (2000) use it to examine the relationship between schooling and growth.

Things are different in China. Parents typically make decisions about children's educational investment under binding credit constraints. Parents invest in their children, partially from altruistic parental love and partially in the interest of an ensured retirement consumption. It is difficult to differentiate one from the other but due to China's poor social security system, the latter could be more important, so we emphasize it.

\section{Measurement of Human Capital}

There are various approaches to measuring human capital in the literature. Mankiw et al. (1992) assume a human capital production technology identical to that of physical capital and use the proportion of the adult population enrolled in secondary school as a proxy for human capital investment. However, the school enrollment does not adequately measure the aggregate stock of human capital available contemporaneously as an input in production. It seems inappropriate to use it as a stock variable.

More recent studies (e.g. Hall and Jones, 1999; Bils and Klenow, 2000) define

human capital as $H_{i}^{y}=\exp ^{\varphi\left(e_{i}^{y}\right)} L_{i}^{y}$, where $\varphi(\cdot)$ reflects the efficiency of a unit of 
labor with $e_{i}^{y}$ years of schooling relative to one with no schooling $(\varphi(0)=0)$. The derivative $\varphi^{\prime}\left(e_{i}^{y}\right)$ is the return to schooling estimated in a Mincerian wage regression (Mincer, 1974).

We take the more recent approach to measure human capital because it ensures that our estimates of human capital are consistent with the private return to schooling seen in the micro data. Our definition is similar to that of Young (2003) and Wang and Yao (2003) in that it takes both the quantity and the quality of the labor force into consideration.

\section{Calibration}

\section{Data and Measurement Issues}

In our model, a period is 25 years. To account for the effect of the OCP, we must cover the periods both before and after its enforcement. The model is calibrated to Chinese data from 1975 to 2000. In 1975, the OCP had not yet been introduced. In 2000, the OCP’s impact on demographic structure emerges. The main parameters can be calibrated based on the two periods. To explore the effect of the OCP, we compare it to a counterfactual experiment without the OCP. We also discuss the model's implication for China’s long-term growth in 2025 and 2050.

\section{Demographic Structure}

Our data cover three periods $(1975,2000,2025)$ of China's demographic structure gathered from World Population Prospects: The 2010 Revision (United Nations, Department of Economic and Social Affairs, Population Division, 2011), which provides detailed population distribution by 5-year age groups in 5-year intervals (1950-2010). It also gives the population prospects from 2010 to 2100 . We define 
children as aged 24 years and below, young adults as aged 25 to 49 years and the elderly as aged 50 years and above. The results are in Table 1. For 2025, we use the estimated population under medium-fertility variant.

\section{Physical Capital Stock}

Many papers have reported estimates of the capital stock in the course of estimating productivity growth in China (e.g. Chow and Li, 2002; Huang et al., 2002; Young, 2003). The estimates of Bai et al. (2006) regarding the capital stock in China differ from these earlier estimates in two principal ways. First, they make use of the updated data reported by China’s National Bureau of Statistics (NBS) after the 2004 census. Second, they calculate the capital stock in market prices rather than in constant prices. ${ }^{10}$ We follow the method of Bai et al. (2006) and use their updated estimates of the capital stock. We take 1978 as the base year to generate real capital stock.

\section{Human Capital Stock}

In our model, human capital is measured as a function of years of schooling and current labor force. The current labor force is the population aged 25 to 49 years in the current period. The data on years of schooling are calculated from Barro and Lee (2000, 2010). Their estimation procedure is a perpetual inventory method that uses the census/survey observations on attainment as benchmark stocks and new school entrants as flows that are added to the stocks with an appropriate time lag. They provide a detailed data set on educational attainment by 5-year age groups over 5-year intervals (1950-2010). Using their data, we construct the number of years of schooling for aged 25 to $49, e_{t}^{y}$, as

$$
e_{t}^{y}=\sum_{a=1}^{5} l_{t}^{a} e_{t}^{a}
$$

\footnotetext{
${ }^{10}$ We thank the authors and Zhenjie Qian, their RA, for providing the updated data.
} 
where $l_{t}^{a}$ is the population share of group $a$ in the population aged 25 to 49 and $e_{t}^{a}$ is the number of years of schooling for the age group $a$ ( $a=1: 25-29$ age group, $a=2: 30-34$ age group,..., $a=5: 45-49$ ). The number of years of schooling for the age group $a$ in time $t$ is

$$
e_{t}^{a}=\sum_{j=1} h_{j, t}^{a} \operatorname{Dur}_{j, t}^{a}
$$

where $h_{j}^{a}$ is the fraction of group $\alpha$ who have attained the educational level $j=$ pri,sec,ter, (coresponding to primary, secondary and tertiary education, respectively) and Dur indicates the corresponding duration in years. The great increase in educational attainment of China's labor force can be seen in Figure 3.

\section{Output}

The output data come from the China Statistics Yearbook (CSY). We take 1978 as the base year to generate real GDP.

\section{Calibration Strategy}

Our basic strategy is to calibrate the parameters such that the following two equations hold.

$$
\begin{gathered}
\beta \frac{\left(c_{t}^{y}\right)^{\gamma}}{\left[\exp \left(\delta e_{t}^{c}\right) L_{t+1}^{y}\right]^{\alpha+\gamma-\alpha \gamma}}\left(\lambda(1-\alpha) A_{t+1} K_{t+1}^{\alpha}\right)^{1-\gamma}(1-\alpha) \cdot L_{t+1}^{y} / L_{t}^{c}=p_{t} \\
c_{t}^{y}+p_{t} \exp \left(\delta e_{t}^{c}\right) L_{t}^{c}=(1-\lambda)(1-\alpha) Y_{t}-L_{t}^{c} c^{s u b}
\end{gathered}
$$

Specifically, the steps of calibration are conducted as follows:

1. (Before the OCP) Using the output data and children's education in 1975 and 2000, ${ }^{11}$ we calibrate $p_{1975 .}$ Note that $c_{1975}$ and $p_{1995}$ are

\footnotetext{
${ }^{11}$ Children's education in 1975 is not directly observable in the current year, but it equals the young adults' education in 2000 .
} 
simultaneously calibrated.

2. (Benchmark) Assume that $e_{2025}^{y}=11.4,{ }^{12}$ and TFP and capital stock's growth in 2000-2025 keep the same as 1975-2000, we calibrate $p_{2000}$ to fit the model.

3. (Cases I, II and III) We then conduct three counterfactual experiments based on three different estimates (from high to low) of the OCP's impact on China's demographic structure. We use the calibrated model to simulate the possible impact of the OCP on education and output under these counterfactual scenarios.

Step I corresponds to the period before the OCP, which is calibrated to show how the model fits the data. It captures a prior belief. Step II provides the basic benchmark under the OCP. Step III conducts three counterfactual experiments to evaluate the impact of the OCP on educational output, based on the three estimates of counterfactual demographic structure.

Note that this study focuses on how OCP's impact under different scenarios designed in Step III. Although the number of $e_{2025}^{y}$ in step II is set by a linear prediction here, it won’t change our main results.

\section{The Three Estimates of Demographic Structure}

There is no consensus on the OCP's influence over China's demographic structure. The official claim is that the OCP prevented 400 million births in China from 1978 to 2008. Although this is often cited by the government, it is hotly debated. A common critique is that the fertility rate usually decreases when an economy grows, according

\footnotetext{
${ }^{12}$ We get the number by assuming the young adults' years of schooling grows from 2000 to 2025 at the same speed as from 1975 to 2000.
} 
to the experiences of other industrialized countries. Thus, the effect could be exaggerated. Thus, we take the officially reported number as a high estimate and also consider moderate and low estimates (200 and 100 million). The estimates are adjusted according to the time period for our model. ${ }^{13}$ The three estimates are presented in Table 3.

\section{Parameters}

Table 2 summarizes the parameters in the calibration. Following Liao (2012), we choose a CRRA preference with a risk-aversion parameter of $\gamma=0.5$, and the subjective discount factor $\beta=0.9557$. It is also assumed that these preference parameters are constant over time.

For the technology parameter, we first take $K$ from Bai et al. (2010). Because the labor share has been approximated at 50 percent in China (Wang and Yao , 2003; Brandt and Zhu, 2010), we set $\alpha=0.5$. According to Heckman and Li (2004) and Zhang et al. (2005), the return to years of schooling is about 10-11 percent for the late twentieth century in China. We then set $\delta=0.10$.

The other parameters of exogenous driving force include $c^{\text {sub }}, \lambda, p$. The average cost of rasing a child (excluding education costs) is 22.7 percent of a family’s income, which follows Liao's (2012) calculations based on Ye and Ding’s (1998) survey. ${ }^{14}$ So $c^{\text {sub }}$ is calculated from our data on family income and the childhood population. We

\footnotetext{
${ }^{13}$ Take the high estimate for example. Because our period is 1975-2000, we compute the population aged 24 and below as $L_{2000, n}^{c}=L_{2000}^{c}-400000 * 22 / 30$. We also project it into 2025 as population aged 25-49, using a same survival rate as the rate under the OCP.

${ }^{14}$ Ye and Ding (1998) compare the cost of child care in Xiamen to that in Beijing. In Xiamen, a child's care cost about 29 percent of a family's annual income in 1995. The percentage was 16.4 percent in Beijing. Thus, the average cost of child care is 22.7 percent.
} 
set the share of young adults' wage income transferred to their elderly parents as $\lambda=0.15$.

The parameter for educational cost $p$ is calibrated as discussed in the calibration strategy.

\section{The Effects of the OCP}

\section{Results for 1975}

Table 4 shows the calibration results for each generation's expenditure (consumption and education) in 1975. The data in the first row give the share of expenditure by each group while those in the second row give the total expenditure and those in the third row give per capita expenditure. We set the parameters of the share of expenditure on child care and retired adults as 23 and 15 percent, respectively.

The young adults would spend 30 percent on their own consumption and 32 percent on their children's educational investment. The average consumption of young adults and retired adults is close. These results provide confidence for our further analysis.

\section{The OCP's Influence: Three Counterfactual Experiments}

Panel (a) of Table 5 shows the calibration results of each generation's expenditures (consumption and education) in 2000. If we believe that the young adults' years of schooling reach 11.4 in 2025, then the output becomes 207,788.15. Thus, the growth rate could reach 8.4 percent from 2000 to 2025, whereas it remains at 7.0 percent from 2010 to 2025. The young adults would spend 33 percent on their own consumption and 29 percent on their children's education.

We then turn to our main results on the OCP's influence by conducting three counterfactual experiments assuming that there was no OCP in 1978. 
Under high estimates (Case I shown in Panel (b)), which assume that the number of children increases by 56.4 percent without the OCP, the young adults' years of schooling would decrease to 5.12 in 2025 . The young adults would spend 25 percent of their income on their own consumption and 24 percent on their children's education. As a contrast, they must spend 35 percent of their income on child care because there are many more children to feed.

Under moderate estimates (Case II shown in Panel (c)), which assume that the number of children increases by 28.2 percent without the OCP, the young adults' years of schooling would decrease less, reaching 8.07. The young adults would spend 29 percent of their income on their own consumption and 27 percent on their children's education. The child care costs would decrease to 29 percent because the number of children would not be as big as in Case I.

Under low estimates (Case III shown in Panel (d)), which assume that the number of children increases by 28.2 percent without the OCP, the young adults' years of schooling would decrease to 9.67, which would be higher than in Case II. The young adults would spend 31 percent of their income on their own consumption and 28 percent on their children's education. The child care costs would decrease to 26 percent.

Taken together, the results indicate that young adults will increase the investment in their children's education when the OCP comes into effect. To ensure their retirement consumption, the more strictly the policy is implemented, the fewer children young adults will have and the more they will invest in their children's education. The behavioral response of substituting quantity with quality (education) will offset the OCP's negative influence on output. Because the presence of fewer children substantially reduces the child care costs, the output under the OCP will be 
higher than that without the OCP due to the income effect. Taking moderate estimates as an example, the output would be 199153.50 without the OCP, which is 4.2 percent lower than the output under the OCP.

\section{Conclusion}

We claim that the demographic changes caused by the one child policy (OCP) may not harm China's long-term growth. This attributes to the higher human capital induced by the intergenerational transfer arrangement under China's poor social security system. Parents raise their children and depend on them for support once they have reached an advanced age. Thus, the decrease in the number of children prompted by the OCP results in the parents investing more in their children's education to ensure their retirement consumption. In addition, the decreased child care costs strengthen the educational investment through the income effect. Our numerical simulation proves these insights. Using a calibrated model, we compare a benchmark with the OCP to three counterfactual scenarios without the OCP. The output under the OCP is about 4 percent higher than without the OCP in 2025 under moderate estimates. The output gain comes from the greatly increased educational investment in fewer children (years of schooling 11.4 rather than 8.1). Our model sheds new light on the prospects of China's long-term growth by emphasizing the OCP's growth enhancing role through human capital under the intergenerational transfer arrangement, which also provides a motive for the popular quantity-quality tradeoff theory.

Human capital could still play an important role in China. We assume that the average years of schooling will reach 11.4 in 2025. Compared to 13.4 years of schooling in the US in 2010, there is still some potential for China to maintain its high 
growth in the future. Thus, we think that the disappearing demographic gift will not hurt China’s growth in the next several decades.

\section{Appendix: Proof for Proposition 1.}

Proof. Proposition 1 is proven by contradiction.

Rewrite the first-order equation (2) as

$$
\begin{aligned}
& \beta \frac{\left((1-\lambda)(1-\alpha) Y_{t}-L_{t}^{c} c^{s u b}-p_{t} \exp \left(\delta e_{t}^{c}\right) L_{t}^{c}\right)^{\gamma}}{\left[\exp \left(\delta e_{t}^{c}\right) L_{t+1}^{y}\right]^{\alpha+\gamma-\alpha \gamma}} \\
& \left(\lambda(1-\alpha) A_{t+1} K_{t+1}^{\alpha}\right)^{1-\gamma}(1-\alpha) \cdot \pi_{t+1}=p_{t} .
\end{aligned}
$$

Simplify it by assumption,

$$
\frac{\left(a-L_{t}^{c} c^{\text {sub }}-p_{t} \exp \left(\delta e_{t}^{c}\right) L_{t}^{c}\right)^{\gamma}}{\left[\exp \left(\delta e_{t}^{c}\right) L_{t}^{c}\right]^{\alpha+\gamma-\alpha \gamma}}=b .
$$

where $a, b$ are constant.

(1) Assume that $e_{t}^{c}$ decreases when $L_{t}^{c}$ decreases. Then in the left part of the equation the numerator increases while the denominator decreases. This contradicts the constant in the right part.

(2) Assume that $\exp \left(\delta e_{t}^{c}\right) L_{t}^{c}$ decreases (with an increased $e_{t}^{c}$ ) when $L_{t}^{c}$ decreases. Then, in the left part of the equation the numerator increases while the denominator decreases. This contradicts the constant in the right part. So $\exp \left(\delta e_{t}^{c}\right) L_{t}^{c}$ increases when $L_{t}^{c}$ decreases, which leads to an increase in output.

QED. 


\section{References}

[1] Bai, C.; Hsieh, C. \& Qian, Y. The Return to Capital in China, Brookings Papers on Economic Activity, Brookings Institution Press, 2006, 61-101.

[2] Banerjee, A.; Meng, X. \& Qian, N. The Life Cycle Model and Household Savings: Micro Evidence from Urban China mimeo, Yale University, 2010.

[3] Barro, R. \& Lee, J. International data on educational attainment updates and implications National Bureau of Economic Research, 2000.

[4] Barro, R. \& Lee, J. A new data set of educational attainment in the world, 1950-2010 National Bureau of Economic Research, 2010.

[5] Becker, G. \& Lewis, H. On the Interaction between the Quantity and Quality of Children, The Journal of Political Economy, 1973, 279-288.

[6] Ben-Porath, Y. The production of human capital and the life cycle of earnings, The Journal of Political Economy, 1967, 75, 352-365.

[7] Bils, M. \& Klenow, P. Does schooling cause growth? American Economic Review, 2000, 1160-1183.

[8] Bloom, D. \& Williamson, J. Demographic transitions and economic miracles in emerging Asia The World Bank Economic Review, World Bank, 1998, 12, 419-455.

[9] Boserup, E. Population and Technical Change: A Study of Long-Term Trends, Chicago: University of Chicago Press, 1981.

[10] Brandt, L. \& Zhu, X. Accounting for China's growth, IZA Discussion Paper, 2010.

[11] Cai, F. Demographic Transition, Demographic Dividend, and Lewis Turning Point in China, Economic Research Journal, 2010, 4, 002.

[12] Chow, G. \& Li, K. China's Economic Growth: 1952-2010, Economic Development and Cultural Change, 2002, 51, 247-256.

[13] Hall, R. \& Jones, C. Why Do Some Countries Produce So Much More Output Per Worker Than Others? The Quarterly Journal of Economics, 1999, 114, 83-116.

[14] Heckman, L. Heterogeneity, Selection Bias and the Return to Education: A Empirical Analysis Based on Chinese Micro-Data, Economic Research Journal, 2004, 4, 9.

[15] Herd, R.; Hu, H. \& Koen, V. Providing greater old-age security in China OECD Publishing, 2010. 
[16] Huang, Yongfeng; Ren, Ruoen; and Liu, Xiaosheng, 2002. "Estimating Capital Stock in China's Manufacturing Sector Using Perpetual Method,” Economics Quarterly, (in Chinese), Vol.1, No.2.

[17] Jones, C. Growth: with or without scale effects? The American Economic Review, 1999, 89, 139-144.

[18] Mincer, J. Schooling, Experience, and Earnings, New York: Columbia University Press, 1974.

[19] Liao, P. The one-child policy: A macroeconomic analysis Journal of Development Economics, 2012.

[20] Li, H. \& Zhang, J. Do high birth rates hamper economic growth? The Review of Economics and Statistics, MIT Press, 2007, 89, 110-117.

[21] Li, H.; Zhang, J. \& Zhu, Y. The quantity-quality trade-off of children in a developing country: Identification using Chinese twins, Demography, Springer, 2008, 45, 223-243.

[22] Li, Y.; Whalley, J.; Zhang, S. \& Zhao, X. The Higher Educational Transformation of China and Its Global Implications, The World Economy, 2011, 34, 516-545.

[23] McElroy, M. \& Yang, D. Carrots and sticks: fertility effects of China's population policies The American economic review, 2000, 90, 389-392.

[24] Rosenzweig, M. \& Zhang, J. Do Population Control Policies Induce More Human Capital Investment? Twins, Birth Weight and China’s “One-Child” Policy, The Review of Economic Studies, Oxford University Press, 2009, 76, 1149-1174.

[25] Qian, N. Quantity-Quality and the One Child Policy: The Only-Child Disadvantage in School Enrollment in Rural China, National Bureau of Economic Research, 2009.

[26] Samuelson, P. An exact consumption-loan model of interest with or without the social contrivance of money, The journal of political economy, 1958, 66, 467-482.

[27] Romer, P. Endogenous Technological Change, Journal of Political Economy, 1990, 98, 71-102.

[28] Romer, P. Increasing returns and long-run growth, The Journal of Political Economy, 1986, 1002-1037.

[29] World Bank: China 2030: Building a Modern, Harmonious, and Creative High-Income Society, 2012.

[30] Wei, S. \& Zhang, X. The Competitive Saving Motive: Evidence from Rising Sex 
Ratios and Savings Rates in China, Journal of Political Economy, 2011, 119, 511-564. [31] Ye, W. Z. \& Ding, Y. The Cost of Child Care in Xiamen Special Economic Zone, China Population and Economics (in Chinese), 1998, 6, 24-57.

[32] Young, A. Gold into Base Metals: Productivity Growth in the People’s Republic of China during the Reform Period, Journal of Political Economy, 2003, 111, $1220-1261$.

[33] Zhang, X.; Yang, J. \& Wang, S. China has reached the Lewis turning point, China Economic Review, 2011, 22, 542-554.

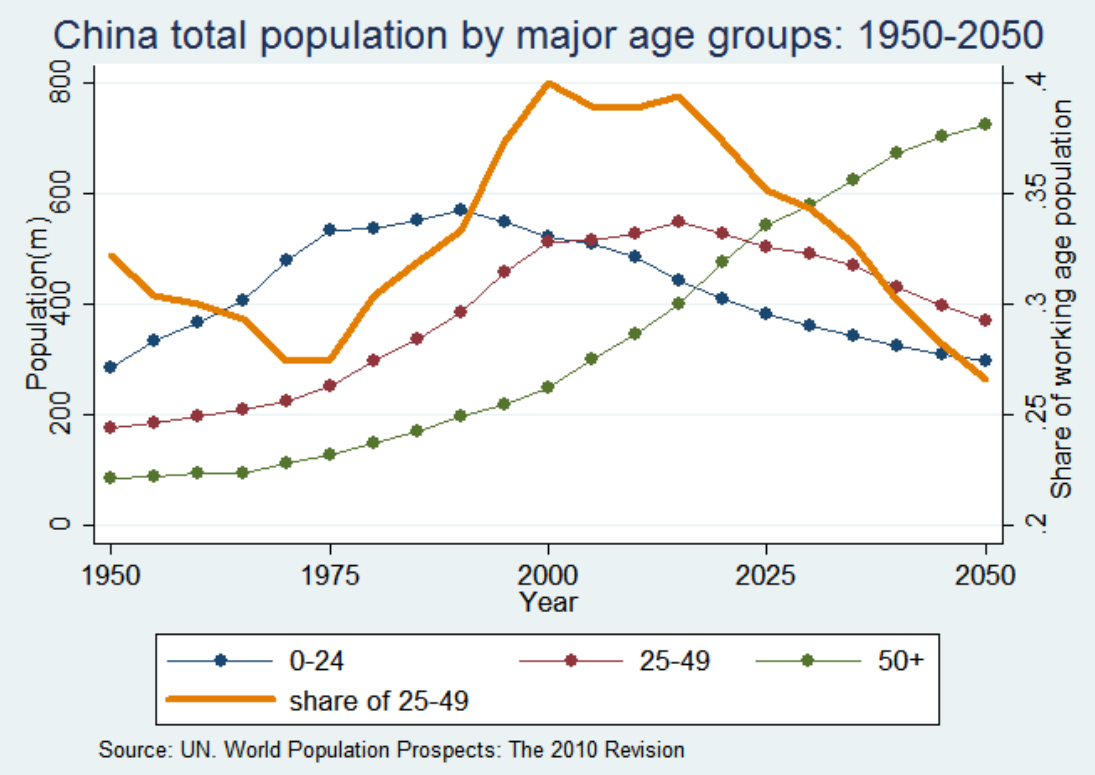

Figure 1: Population by age group 1950-2050 

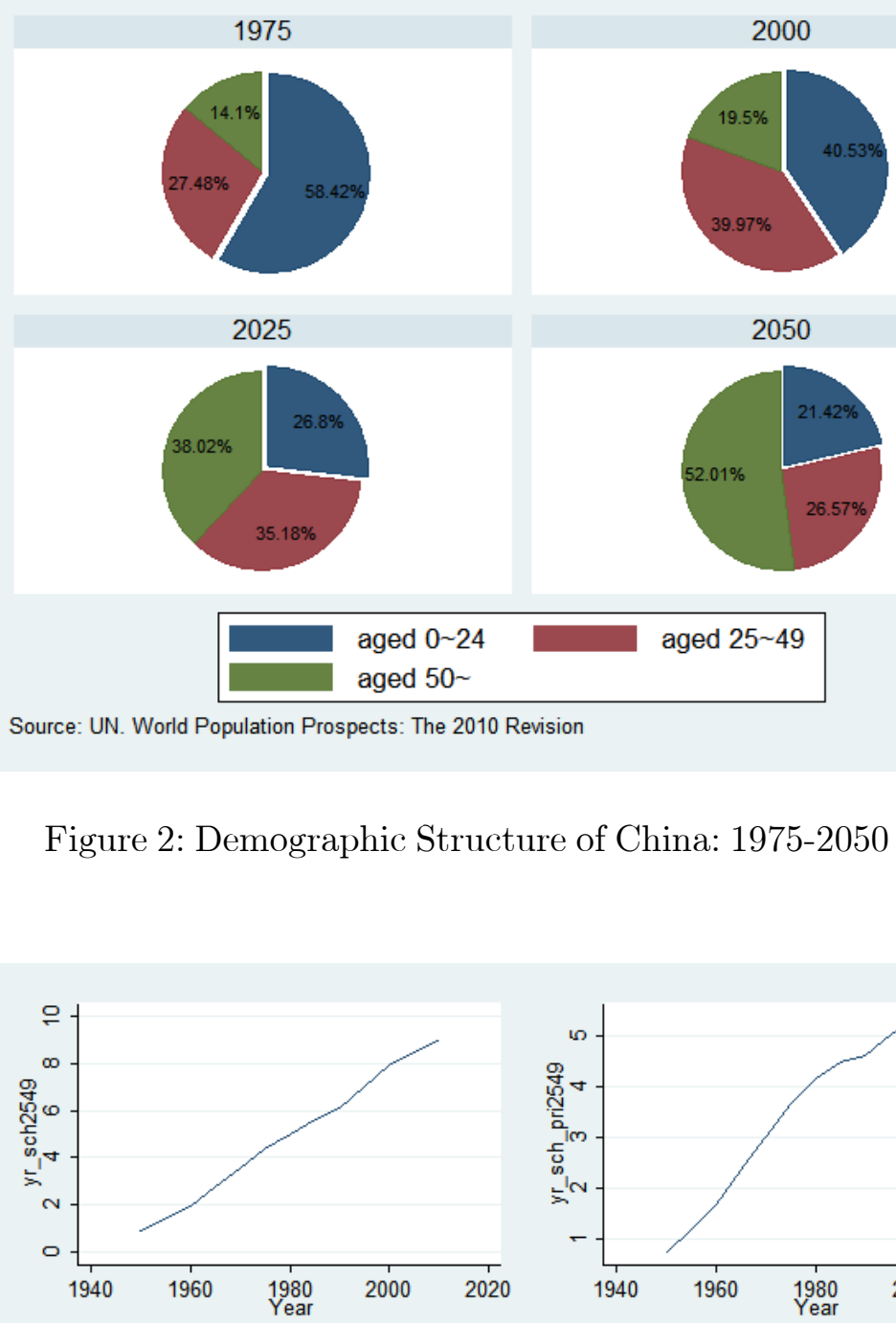

2050

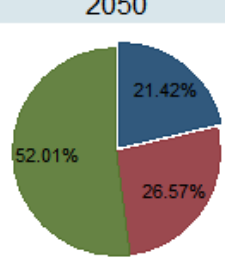

aged $25 \sim 49$

Source: UN. World Population Prospects: The 2010 Revision

Figure 2: Demographic Structure of China: 1975-2050
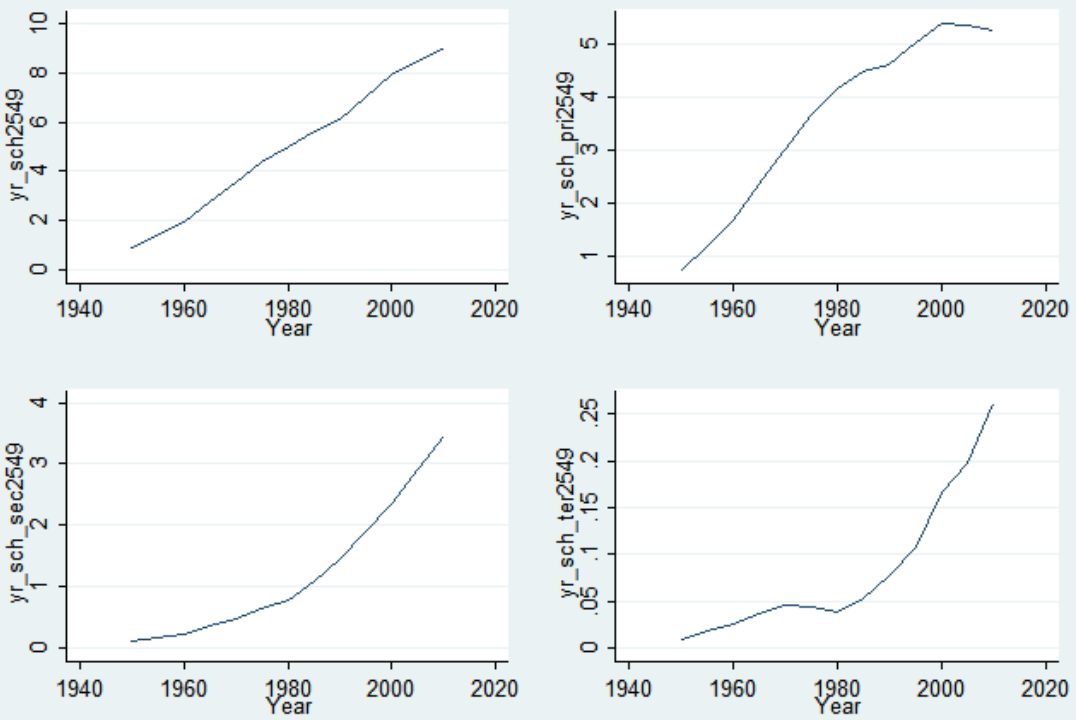

Source: calculated based on Barro and Lee (2010)

Figure 3: Educational Attainment in China: 1950-2010 

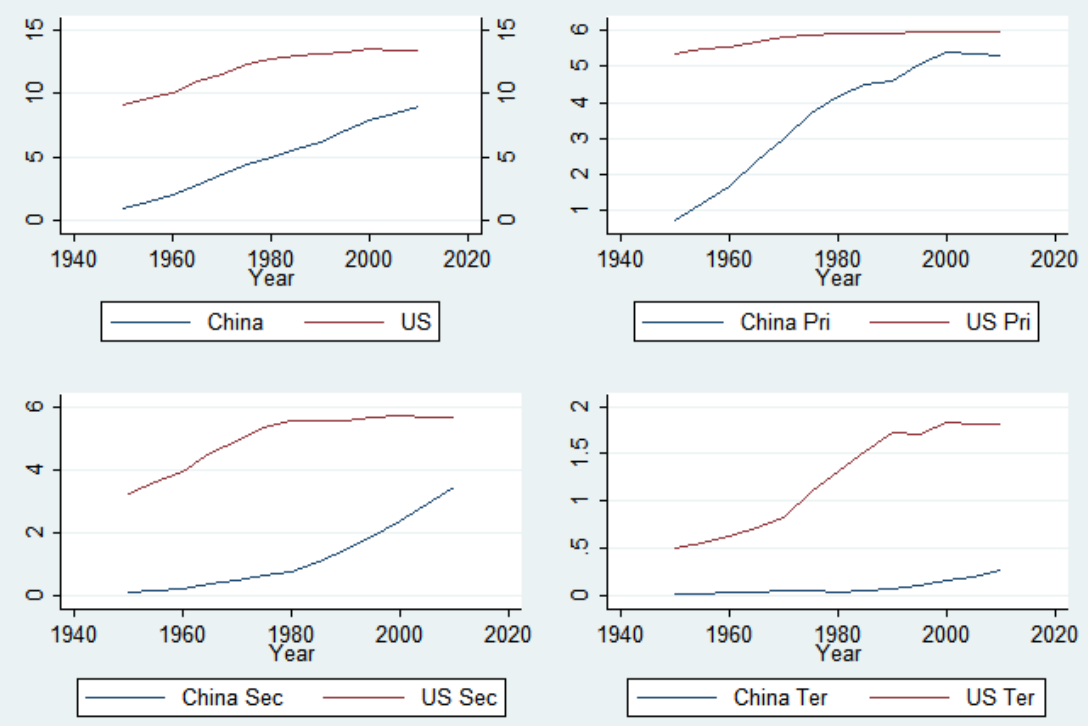

Source: calculated based on Barro and Lee (2010)

Figure 4: Education: China and US

Table 1. Age Structure 1975-2025 (UN)

\begin{tabular}{|c|c|c|c|c|c|c|c|}
\hline year & pop & pop0024 & pop2549 & pop5099 & child/pop & labor/pop & old/pop \\
\hline 1950 & 550771.4 & 286403.6 & 177426.0 & 86941.8 & 52.0 & 32.2 & 15.8 \\
\hline 1975 & 915041.0 & 534550.0 & 251425.0 & 129065.9 & 58.4 & 27.5 & 14.1 \\
\hline 2000 & 1282736.6 & 519884.7 & 512712.6 & 250139.3 & 40.5 & 40.0 & 19.5 \\
\hline 2025 & 1425626.0 & 382072.3 & 501569.9 & 541983.8 & 26.8 & 35.2 & 38.0 \\
\hline 2050 & 1393942.4 & 298623.7 & 370396.1 & 724922.7 & 21.4 & 26.6 & 52.0 \\
\hline
\end{tabular}

Table 2. Parameters for Calibration

\begin{tabular}{ccccc}
\hline & $\mathbf{1 9 7 5}$ & $\mathbf{2 0 0 0}$ & $\mathbf{2 0 2 5}$ & Target/Method \\
\hline & & & Preference \\
\hline & 0.9557 & 0.9557 & 0.9557 & Liao (2012) \\
\hline
\end{tabular}




\begin{tabular}{|c|c|c|c|c|}
\hline$\gamma$ & 0.5 & 0.5 & 0.5 & Liao (2012) \\
\hline$\alpha$ & 0.5 & 0.5 & 0.5 & Brandt and Zhu (2010) \\
\hline \multicolumn{5}{|c|}{ Technology } \\
\hline$A$ & 0.0798 & 0.1402 & 0.2464 & by caculation \\
\hline$K$ & 4429.8 & 44816.6 & 453414.8 & Bai et al (2006) \\
\hline$\delta$ & 0.10 & 0.10 & & Heckman and Li (2005) \\
\hline \multicolumn{5}{|c|}{ Exogenous Driving Force } \\
\hline$c^{\text {sub }}$ & 0.0007 & 0.0060 & & by calculation \\
\hline$\lambda$ & 0.15 & 0.15 & 0.15 & by calculation \\
\hline \multicolumn{5}{|c|}{ Calibrated Parameter } \\
\hline$p$ & 0.0004 & 0.0025 & & calibrated \\
\hline
\end{tabular}

Table 3. Demographic Structure under Different Predictions

\begin{tabular}{cccc}
\hline \multicolumn{5}{c}{ pop0024 } & pop2549 & pop5099 \\
\hline Benchmark & With OCP & & \\
1975 & 534550.0 & 251425.0 & 129065.9 \\
2000 & 519884.7 & 512712.6 & 250139.3 \\
2025 & 382072.3 & 501569.9 & 541983.8 \\
2050 & 298623.7 & 370396.1 & 724922.7 \\
Case I & NO OCP: HIGH & \\
1975 & 534550.0 & 251425.0 & 129065.9 \\
2000 & 813218.0 & 512712.6 & 250139.3 \\
2025 & 597648.1 & 784569.5 & 541983.8 \\
2050 & 467115.4 & 579383.9 & 1133944.1 \\
Case II & NO OCP: MOD & \\
1975 & 534550.0 & 251425.0 & 129065.9 \\
\hline
\end{tabular}




\begin{tabular}{rrrr}
\hline 2000 & 666551.4 & 512712.6 & 250139.3 \\
2025 & 489860.2 & 643069.7 & 541983.8 \\
2050 & 382869.5 & 474890.0 & 929433.4 \\
Case III & NO OCP: LOW & \\
1975 & 534550.0 & 251425.0 & 129065.9 \\
2000 & 593218.0 & 512712.6 & 250139.3 \\
2025 & 435966.2 & 572319.8 & 541983.8 \\
2050 & 340746.6 & 422643.1 & 827178.0 \\
\hline
\end{tabular}

Table 4. Calibration Results in 1975

\section{Before the OCP}

\begin{tabular}{ccccc}
\hline & (1) worker & (2) child care & (3) education & (4) old \\
Share(\%) & 0.30 & 0.23 & 0.32 & 0.15 \\
Tot. Expend. & 461.02 & 350.13 & 499.20 & 231.24 \\
Avg. Expend. & 183.36 & 65.50 & 93.39 & 179.16
\end{tabular}

Table 5. Impact of OCP in 2000

\begin{tabular}{ccccc}
\hline Panel (a) & Benchmark & With OCP & & \\
\hline & output2025 & edu2025 & & \\
& 207787.15 & 11.40 & & \\
& (1) worker & (2) child care & (3) education & (4) old \\
Share(\%) & 0.33 & 0.23 & 0.29 & 0.15 \\
\hline
\end{tabular}




\begin{tabular}{|c|c|c|c|c|}
\hline Tot. Expend. & 4605.60 & 3119.31 & 4048.32 & 2077.63 \\
\hline Avg. Expend. & 898.28 & 600.00 & 778.70 & 830.59 \\
\hline \multirow[t]{4}{*}{ Panel (b) } & Case I & NO OCP: HIGH & & \\
\hline & output2025 & edu2025 & & \\
\hline & 189866.47 & 5.12 & & \\
\hline & (1) worker & (2) child care & (3) education & (4) old \\
\hline Share(\%) & 0.25 & 0.35 & 0.24 & 0.15 \\
\hline Tot. Expend. & 3513.78 & 4879.31 & 3380.13 & 2077.63 \\
\hline Avg. Expend. & 685.33 & 600.00 & 415.65 & 830.59 \\
\hline \multirow[t]{4}{*}{ Panel (c) } & Case II & NO OCP: MOD & & \\
\hline & output2025 & edu2025 & & \\
\hline & 199153.50 & 8.07 & & \\
\hline & (1) worker & (2) child care & (3) education & (4) old \\
\hline Share(\%) & 0.29 & 0.29 & 0.27 & 0.15 \\
\hline Tot. Expend. & 4055.03 & 3999.31 & 3718.89 & 2077.63 \\
\hline Avg. Expend. & 790.90 & 600.00 & 557.93 & 830.59 \\
\hline \multirow[t]{4}{*}{ Panel (d) } & Case III & NO OCP: LOW & & \\
\hline & output2025 & edu2025 & & \\
\hline & 203544.74 & 9.67 & & \\
\hline & (1) worker & (2) child care & (3) education & (4) old \\
\hline Share(\%) & 0.31 & 0.26 & 0.28 & 0.15 \\
\hline Tot. Expend. & 4329.22 & 3559.31 & 3884.70 & 2077.63 \\
\hline Avg. Expend. & 844.38 & 600.00 & 654.85 & 830.59 \\
\hline
\end{tabular}

